\title{
O Jovem Hegel: escritos teológicos dos períodos de Stuttgart a Iena
}

\section{The Young Hegel: theological writings to the periods from Stuttgart to Iena}

\author{
CINTHIA ALMEIDA LIMA ${ }^{1}$
}

Resumo: O estudo da filosofia madura de Hegel não é uma tarefa fácil. Suas obras são densas e de difícil compreensão, pelo menos ao que parece numa primeira leitura. Mais compreensíveis, contudo, parecem ser seus escritos de juventude. Quando jovem, Hegel viveu nas cidades de Stuttgart, Tübingen, Berna, Frankfurt am Main e Iena, escreveu uma variedade de textos analisando o judaísmo, o cristianismo e outras religiões, esses conhecidos como "escritos teológicos". Nesses estudos, o jovem Hegel procura investigar as condições para que a religião cristã de sua época resgatasse os ideais solidários, fraternais e igualitários do cristianismo primitivo, original, ou seja, a "inteireza espiritual" ensinada por Jesus a seus discípulos. Mas, além disso, os escritos teológicos de Hegel servem de ponto de partida para um entendimento da relação estreita entre filosofia e religião.

Palavras-Chave: Jovem Hegel. Idealismo alemão. Teologia.

Abstract: Studying Hegel's late philosophy is not an easy task. His works are dense and difficult to understand, at least in a first sight. However, his early writings seem to be more accessible. During his youth, Hegel lived in the cities of Stuttgart, Tübingen, Bern, Frankfurt am Main and Jena, wrote a variety of texts analyzing Judaism, Christianity and other religions, these texts are known as theological writings. In these studies, the young Hegel investigates the conditions for the Christian religion of his time to rescue the ideals of solidarity, fraternity and egalitarianism of primitive, original Christianity, that is, the "spiritual wholeness" taught by Jesus to his disciples. But, more than that, the theological writings of Hegel serve as a starting point for an understanding of the complex relationship between religion and philosophy.

Keywords: Young Hegel. German Idealism. Theology.

\section{Introdução}

Georg Wilhelm Friedrich Hegel (1770-1831), idealista alemão, filósofo considerado por alguns estudiosos como obscuro e de difícil compreensão, nascido em Stuttgart, dedicou-se em seus escritos de juventude, entre os anos de 1788 e 180o, a refletir sobre religião. Inicialmente, Hegel foi estudante do seminário teológico protestante de Tübingen, onde também teve seus primeiros contatos com a filosofia. Neste renomado seminário, conheceu o eminente filósofo Joseph von Schelling, bem como o poeta Friedrich Hölderlin.

O filósofo viveu na considerada época de ouro da literatura alemã, envolveu-se

\footnotetext{
${ }^{1}$ Graduada em Direito, com especialização em Direito do Trabalho pela Universidade Tiradentes de Sergipe e especialização em Direito Penal e Processo Penal pela Estácio FASE. Advogada inscrita na Ordem dos Advogados do Brasil - Seccional Sergipe. Graduanda e mestranda em Filosofia, bolsista voluntária do PIBIC 2015/2016 no plano de trabalho "Os escritos teológicos do jovem Hegel" vinculado ao projeto "Idealismo alemão e cristianismo: aproximações e divergências", na Universidade Federal de Sergipe. E-mail: advcinthialima@gmail.com.
} 
com algumas ideias do romantismo, mesmo sendo um crítico dos românticos. São influências culturais na formação do jovem e maduro Hegel: cultura grega; pensamento iluminista; filosofia kantiana; escritos de Herder, Jacobi, Hölderlin, Fichte, Schelling, Schiller e Goethe. Foi ainda considerado um idealista absoluto, cujas discussões dessa corrente filosófica tiveram por base a publicação da Crítica da Razão Pura de Immanuel Kant. Mas, a filosofia da história, o papel do cristianismo e principalmente a Reforma Protestante são pontos cruciais nos estudos teológicos de Hegel, assim como o desenvolvimento da concepção de liberdade.

O pensamento de Hegel desta época foi influenciado consideravelmente pelos ideais iluministas e a Revolução Francesa, a qual qualificou como uma "queda gloriosa”, declarando o filósofo admiração pela figura de Napoleão Bonaparte. E quando o imperador foi vencido no ano 1814, o jovem Hegel "referiu-se a isto como um acontecimento trágico, o espetáculo de um gênio grandioso destruído pela mediocridade" (SINGER, 2003. p. 12).

Ao completar seus estudos teológicos em Tübingen, Hegel foi tutor particular em Berna e ainda em Frankfurt, mas pensamentos e leituras filosóficas persistiram em sua vida. Após a morte de seu pai em 1799, começou a ensinar na Universidade de Iena, pois, recebeu uma herança irrisória e precisava sobreviver. Ao longo de sua juventude, escreveu alguns ensaios sobre religião, comparou Jesus a Sócrates, em razão deste último se posicionar como questionador do sistema político e religioso grego de sua época, e mesmo tecendo críticas abertas à religião ortodoxa em vários momentos de sua existência, posteriormente, considerou-se um cristão luterano e frequentava cerimônias da referida religião.

Com a ocupação francesa em Iena, Hegel foi trabalhar como editor de um jornal depois que foi fechada a universidade em que lecionava, e em seguida, assumiu a direção da escola secundária de Nuremberg, onde permaneceu por nove anos, ensinando filosofia, além das demais matérias convencionais. Hegel casou-se aos 41 anos com uma moça de família tradicional de Nuremberg, com quem teve dois filhos, mas anteriormente teve um filho ilegítimo. Foi ainda professor de filosofia na Universidade de Heidelberg e ocupou a cátedra de filosofia na Universidade de Berlim de 1818 a 1831, ano de seu falecimento.

Os textos do jovem Hegel, conhecidos até agora, são reunidos em cinco partes, cujos títulos foram atribuídos por Herman Nohl : 1) Religião popular e cristianismo (cinco fragmentos dos períodos de Tübingen e Berna); 2) A vida de Jesus (título conferido por Rosenkranz); 3) A positividade da religião cristã (fragmentos do período de Berna sobre o cristianismo e a positividade cristã); 4) O espírito do cristianismo e seu destino (textos do período de Frankfurt) e 5) Fragmento de sistema de 1800 (dois fragmentos datados do ano de 1800) (BECKENKAMP, 2009, p. 32-33).

O biógrafo Karl Rosenkranz foi o primeiro a despertar sobre a relevância dos 
escritos de mocidade de Hegel (BECKENKAMP, 2009, p. 12). Wilhelm Dilthey, ao escrever sobre o jovem Hegel, apresenta a influência da filosofia moral kantiana nos textos sobre o espírito do cristianismo do período de Berna, bem como analisa o longo manuscrito dedicado à vida de Jesus e os diversos fragmentos ocupados com a positividade da religião cristã, nos quais se trataria da "relação da religião racional com a religião positiva" (BECKENKAMP, 2009, p. 25). Gisela Schüler com base no desenvolvimento da caligrafia de Hegel, instituiu uma datação dos textos do filósofo que é aceita até os tempos atuais (BECKENKAMP, 2009, p. 40).

O objetivo dessa pesquisa é permitir, a quem nunca teve contato com a filosofia de Hegel, o conhecimento da existência dos seus escritos de juventude, e a principal obra consultada para apresentação desse "estudo genético" é O jovem Hegel: formação de um sistema pós-kantiano de Joãozinho Beckenkamp, um dos poucos livros sobre o tema em português, mas sumamente instrutivo.

\section{Período de Stuttgart (até 1788): primeiros estudos da filosofia moral kantiana}

Hegel nasceu em 27 de agosto de 1770 na cidade de Stuttgart, capital do Ducado de Württemberg, lá vivendo até 1788 . Nesse período, inicia seu interesse pela filosofia e cultura grega, bem como a filosofia da história, mesmo sendo ainda muito jovem. Também nessa fase, o jovem filósofo já evidencia um certo amadurecimento ao averiguar uma afinidade entre a arte, a religião e a vida de um povo.

Todavia, o primeiro contato de Hegel com a filosofia moral de Kant, tão decisivo para sua obra madura, não acontece em Tübingen, mas ainda no período de Stuttgart, nos anos de ginásio. O texto que Hegel examina de Ulrich que foi professor de Kant (Eleuterologia ou sobre liberdade e necessidade de 1788) apresenta um problema central da filosofia moral, resolvido por Kant com os recursos da filosofia crítica, qual seja: o problema da relação entre moralidade e liberdade (BECKENKAMP, 2009, p. 46-47).

O excerto de Hegel da resenha do livro de Ulrich, documenta, assim, o fato de que Hegel teve contato com a filosofia kantiana, no caso com um problema que permanecerá central em seu desenvolvimento e no sistema final. Pois o problema da relação entre moralidade e liberdade e o problema ontológico da liberdade e da necessidade, que decorre do primeiro, são tão importantes no pensamento hegeliano quanto foram no pensamento kantiano.

No segundo excerto a ser considerado aqui, tem-se documentado o contato de Hegel, ainda em Stuttgart, com o problema central da filosofia moral, particularmente esmiuçado por Kant em sua segunda Crítica, a saber, o problema do móbil moral da vontade. Este excerto, com o título "Filosofia. Relação da metafísica com a religião", datado de 29 de setembro de 1788 , reproduz quase literalmente a resenha do livro de A. W. Rehberg, Sobre a relação da metafísica com a religião (1787) (BECKENKAMP, 2009, p. 48). 
Além disso, o fato de Hegel escrever, ao mesmo tempo, sobre filosofia grega e história nesse momento de estudante, mostra também uma preocupação em pensar uma filosofia da história, o que ficará mais evidente nos períodos de Berna e Frankfurt. Em 1788, Hegel ganha uma bolsa ducal para estudar Teologia na Universidade Regional de Tübingen.

\section{Período de Tübingen (1788-1793): o problema dos móbeis morais da vontade}

Em Tübingen, Hegel inicia os estudos de teologia protestante luterana, mas não se desvincula totalmente dos ideais iluministas. No ambiente universitário conheceu e fez amizade com Schelling e Hölderlin. No seminário, as meditações de Hegel sobre a religião ficam situadas no problema mais evidente da filosofia moral kantiana, qual seja, o problema dos móbeis morais.

Nessa etapa, o jovem filósofo escreve sobre Religião popular e cristianismo, e segundo Beckenkamp "os textos datados de Tübingen ocupam-se em boa parte de um leque de questões relativas à sensibilidade, falando seguidamente de coração, sentimento, fantasia, amor e vida" (BECKENKAMP, 2009, p. 43). Num texto de 1793, expressões como "pura religião racional", "fé fetichista", "ideal da razão" e "igreja espiritual universal" apontam para a obra de Kant $A$ religião nos limites da simples razão (BECKENKAMP, 2009, p. 45). A religião, para Hegel, passa a ser "momento determinante da vontade em vista da moralidade" (BECKENKAMP, 2009, p. 62).

Para Kant, moral e religião estão unidas estreitamente, sendo que a diferença básica é a linguagem utilizada para expressar os deveres morais e os deveres religiosos. Na moral, os deveres são princípios fundamentais a serem praticados por todo e qualquer ser racional; na religião, os deveres são considerados mandamentos divinos e há uma ideia de ser supremo. Então, Kant entende que o móbil da moralidade é "tão-somente" o respeito pela lei moral, o imperativo categórico que reside na universalização, isto é, na lei universal. O exato princípio moral da religião é apenas a obrigação à lei moral. No entanto, para Hegel, a religião influencia os sentimentos, e a vontade dos homens teria uma posição significativa para a vida de um povo.

Para poder esperar que o sumo bem, do qual nos compete como dever realizar uma das partes constitutivas, torne-se real no todo, a razão prática exige a fé em um Deus e na imortalidade" (GW 1, 91). A representação do sumo bem e a esperança em sua realização constituem "o germe do qual nasce a religião" (GW 1,91), permitindo, assim uma "dedução da religião" (GW 1, 91), expressão tirada de Fichte. A religião que pode ser deduzida com base no conceito do sumo bem e nos postulados da razão prática é, entretanto, uma "pura religião racional, que venera Deus no espírito e na verdade e põe seu serviço tão-somente na virtude" (GW 1, 99). Para a religião racional, o único serviço agradável a Deus é a virtude, ou seja, a observância da lei moral, da qual Ele constitui a fonte e garantia última de 
realização; nos limites da religião simplesmente racional vale "que o serviço que mais agrada a Deus é o agir direito" (GW 1, 96) (BECKENKAMP, 2009, p. 62).

Para Kant, a religião é consequência de sua filosofia moral, e aquela é resultado necessário da moralidade. As igrejas, como instituições religiosas, apenas têm efetividade em sua função, quando motivam o desenvolvimento moral dos seus seguidores. A doutrina pregada pelas igrejas deve estar em consonância com os princípios morais. Para o jovem filósofo, a religião praticada por um povo deve retratar a relação equilibrada entre o fiel e esta mesma comunidade, refletindo, portanto, a liberdade. Ainda reflete que o ser humano deve chegar a tal religião por si mesmo, pelo uso exclusivo da razão, e o conhecimento de todos os deveres reflete também as leis divinas.

Um último aspecto tocado no texto de Kant, e que será fundamental na situação das investigações do jovem Hegel, é a exigência da "passagem da fé das igrejas para a religião racional universal" (Rel., AA VI, 122). A história dos povos mostra que a religião do povo começa com a religião em comunidades ou igrejas, a qual expressa as necessidades naturais desse povo. A religião estatutária que se constitui historicamente chega mesmo a tornar os homens "não receptíveis à religião racional” (Rel. AA VI, 162). Essa religião estatutária ou positiva pode, portanto, constituir mesmo um obstáculo na passagem da religião do povo para a religião racional universal (BECKENKAMP, 2009, p. 63).

No fragmento de Tübingen, a "religião popular" caracteriza-se por elementos sensíveis (alimento da fantasia, da imaginação e alívio do coração) e deve servir de ponte para uma religião racional. Aquela deve ainda influenciar o homem em seu convívio em sociedade, exercendo um papel de "freio" das paixões. O povo deve ser estimulado a uma religião que o faça cumprir a "legislação da razão". A religião popular utiliza-se de imagens de santos e/ou mártires e instrumentos religiosos que satisfazem a fantasia humana e visa despertar os sentimentos bons, altruístas no coração.

Hegel, nessa fase, investiga também que a religião popular deve atender três exigências essenciais para alcance da religião racional.

"I. Seus ensinamentos têm de ser fundados na razão universal. // II. Fantasia, coração e sensibilidade não podem nisto sair vazias. // III. Ela deve ser constituída de tal maneira que todas as necessidades da vida - as ações públicas do Estado - se conectem com ela" (GW 1, 103) (HEGEL apud BECKENKAMP, 2009, p. 68).

No referido fragmento, o cristianismo é refletido por Hegel e tratado como uma religião que não atinge todas as características acima. Para ele, a segunda e terceira exigências não são atendidas pelas práticas cristãs, pois estas não preenchem a 
fantasia e o coração de forma satisfatória e nem envolvem as tarefas de caráter público do povo, diferentemente da religião popular dos gregos, posto que, nesta o homem relaciona-se de maneira mais próxima com a natureza e os deuses são figuras "vivas" que possuem semelhanças físicas, intelectuais e emocionais com os seres humanos.

O cristianismo ao pregar uma adoração a Deus "no espírito e na verdade", como bem explica Beckenkamp (2009, p. 74), pode compatibilizar-se com a religião racional, mas no que tange à religião popular não atende os requisitos necessários, inclusive, quanto à ligação que deve existir entre natureza e espírito.

\section{Período de Berna (1793-1796): religião cristã e sua positividade}

Em Berna, a reflexão filosófica basilar hegeliana está associada à da religião cristã, cuja positividade afasta o ser humano do povo na sua totalidade. Nesse momento, o jovem filósofo estuda de forma mais aprofundada a filosofia moral kantiana, fase conhecida como "kantismo" de Hegel. Os textos mais importantes do período de Berna são: Fragmentos sobre Religião Popular e cristianismo (1793-1794), iniciados em Tübingen, A Vida de Jesus (1795) e A Positividade da Religião Cristã (1795-1796), lembrando que os referidos títulos são conferidos por Nohl. Embora Hegel tenha escrito tais fragmentos que são considerados estudos teológicos, é nas correspondências com Schelling que o interesse do jovem filósofo pela religião cristã é mais clara, cartas que ainda são objeto de estudos pelos pesquisadores de Hegel.

A posição de Kant, primordialmente, em sua filosofia moral, é a de que a legislação moral goza de autonomia racional e qualquer complemento à aludida lei caracterizaria heteronomia da vontade. Para Hegel, somente a união da ideia de Deus com a lei moral traduz a religião autêntica da moralidade.

São expressos, assim, três aspectos que constituem um bom resumo das preocupações de Hegel em Berna. No respeito pela lei moral e pela virtude expressa-se a autonomia da vontade em sua legislação racional. Na doutrina de Cristo encontra-se um núcleo idêntico à moral pura da razão, o que leva ao respeito dos filósofos e ao interesse de Hegel pela figura de Jesus. Mas, se o respeito pela doutrina de Cristo é limitado a seu núcleo moral, o que não coaduna com este é descartado como fonte de heteronomia e criticado por Hegel sob o conceito da positividade da religião cristã. [...] $\mathrm{Na}$ primeira fase desses estudos kantianos em Berna, está no centro de suas atenções a Crítica da razão prática, cuja concepção rigorista da moral e de seus móbeis constitui o fio condutor da análise da doutrina de Jesus, bem como de sua degeneração em positividade no cristianismo posterior (BECKENKAMP, 2009, p. 8o-82).

Nos Fragmentos sobre Religião popular e cristianismo, Hegel defende a indispensabilidade de uma religião racional que esteja em consonância com a religião espontânea de um povo. Percebe-se, nesse momento, uma concepção hegeliana de liberdade no período bernense, que se apresenta necessariamente no vínculo entre o 
homem e a pólis. Porém, o cristianismo é adverso à liberdade, porque com sua característica privada, o "Absoluto" não se concretiza no convívio da cidade, proclamando-se de maneira externa e imperiosa. A religião cristã revela, assim, o afastamento entre o homem e seu íntimo, seu "Si", desvalorizando também a vida pública.

A filosofia moral hegeliana tece críticas ao despotismo, visa à recuperação da liberdade na concretização de uma religião estabelecida na razão e repreende também a positividade do cristianismo. Essa "censura" à religião pode ser encarada ainda como uma maneira de criticar qualquer forma de "alienação política", visto que a religião coopera com o "estado político de sujeição", ou em outras palavras, um "estado de escravidão".

A religião é abordada, portanto, de uma nova perspectiva. Já não é o problema dos móbeis morais que conduz a investigação do fenômeno religioso, mas sua imanente racionalidade ou moralidade. $\mathrm{O}$ que não é redutível à moralidade deve ser criticado em sua heterogeneidade e em sua positividade. Da doutrina de Cristo, alvo principal de Hegel em Berna, é preciso extrair seu núcleo moral; na vida de Jesus, deve-se ser realizado o ideal da virtude, como exigiria Kant em seu escrito sobre a religião (cf. Rel., AA VI, 6o ss.). A perspectiva adotada, assim, é essencialmente a da filosofia moral e religiosa kantiana; animado por ela, Hegel concentra-se na figura de Jesus e passa posteriormente a uma apreciação crítica daquilo que no cristianismo não é redutível ao núcleo moral, quer dizer, sua positividade (BECKENKAMP, 2009, p. 80-81).

Hegel expõe que é necessário tornar subjetiva a religião objetiva, tendo em vista que tal subjetivação é um dos escopos maiores do Estado. O caráter objetivo da religião é composto dos postulados da imortalidade da alma e da existência de Deus, contudo, o caráter subjetivo está na necessidade da razão de unir moralidade e felicidade. A religião objetiva é aquela apreendida ainda na infância e os ensinamentos religiosos são fixados na memória através de aspectos institucionalizados. Já a religião subjetiva é exteriorizada pelas ações e sensações. Qualquer religião só pode ser absorvida quando há condições que possibilitem sua evolução e perpetuação em âmbito social.

Mas o fato do jovem filósofo entender a religião como um complemento do móbil moral afasta-o aqui da filosofia moral de Kant. Hegel percebe a "contradição" que constitui a aplicação da concepção moral kantiana ao fenômeno religioso. $\mathrm{O}$ kantismo de Hegel em Berna passa a ser relativizado, levando-se também em conta os seus estudos da vida de Jesus.

A associação dos postulados da imortalidade da alma e da existência de Deus com a ideia teológica tradicional de um julgamento após a morte, com a consequente recompensa ou punição pela conduta moral ao longo da vida, acaba por constituir um ponto de atrito com 
a doutrina kantiana, na medida em que Hegel identifica o caráter problemático da expectativa de recompensa ou de punição de um ponto de vista moral, pois, como é fácil de constatar, a expectativa da compensação é tanto maior quanto mais pusilânime e mal acostumado o homem, ou seja, aquela expectativa vem na proporção inversa da virtude: "A esperança de uma compensação por sofrimentos padecidos é um pensamento consolador, um pensamento que reclamamos perante a justiça, mas nisso temos de nos acostumar certamente a não ver como injustiça tudo o que acontece contra nossa expectativa, temos de nos acostumar a nos considerar mais dependentes da natureza. [...] $\mathrm{O}$ atrito inicial com e a crítica final do conceito kantiano do sumo bem e da doutrina dos postulados, em Berna, não significam uma ruptura com o kantismo, uma vez que, com a insistência na autonomia da vontade e na pureza da legislação da razão, é mantido e mesmo reforçado o cerne da concepção kantiana da moralidade, com sua separação e contraposição de razão e natureza, moralidade e felicidade, progresso na virtude e destino no mundo. A ruptura definitiva com o kantismo se dá com a crítica precisamente dessa lógica da contraposição, uma crítica que começa a tomar forma apenas em Frankfurt.

No contexto desse kantismo problemático situam-se as investigações sobre a religião cristã que Hegel empreende em Berna. Nelas dominam dois grandes temas, que serão analisados sumariamente em seguida: a figura de Jesus e a positividade da religião cristã (BECKENKAMP, 2009, p. 91-101).

A figura de Jesus e a positividade da religião cristã são temas de maior destaque nos estudos de Hegel ainda nesse período. Em A Religião nos Limites da Simples Razão, obra que influenciou o jovem filósofo, Kant admitia uma religião legitimamente racional, na qual a lei moral, assumida de forma autônoma pela vontade, é representada como lei divina, ou seja, a moral não depende da religião, mas a segunda não pode afastar-se da primeira, ou seja, a religião no pensamento kantiano, não é um móbil da moralidade.

Influenciado pelo pensamento kantiano, Hegel busca apresentar a racionalidade vinculada à figura de Jesus Cristo. A "personificação na pessoa do Cristo" e sua característica de "divindade" são pontos cruciais que expressam a positivação da fé religiosa, mas o foco hegeliano é, além disso, tecer uma crítica a à alienação religiosa, e, consequentemente, política, e com isso também à perspectiva moral kantiana.

Em sua reconstrução histórica de Jesus, Hegel mostra, portanto, sua proximidade com o pensamento moral kantiano, não só na concepção da lei fundamental da moralidade em termos que parafraseiam o imperativo categórico, mas ainda pela adoção do rigorismo moral kantiano, que se expressa na exigência da pureza do móbil moral, não se admitindo como moral senão o cumprimento da lei por respeito à lei (o que Hegel chama agora de "agir no espírito da 
lei”). A pregação de Jesus é reconstruída como uma defesa da autonomia da vontade humana, de que decorre sua dignidade, contra a positividade e heteronomia das leis judaicas: "Jesus lhes respondeu: Se tomais vossos estatutos eclesiásticos e leis positivas como a lei suprema que é dada ao homem, desconheceis a dignidade do homem e sua capacidade de extrair de si mesmo o conceito da divindade e o conhecimento de sua vontade - quem não honra em si mesmo esta capacidade não honra a divindade - , o que o homem pode chamar seu eu e que está acima do túmulo e da decomposição, e determinará por si mesmo a recompensa merecida, é ser capaz de julgar a si mesmo - anuncia-se como razão, cuja legislação não depende de nenhuma outra coisa" (GW 1, 223). [...] As investigações sobre a positividade da religião cristã, levadas a cabo por Hegel em seus últimos tempos de Berna, visam lançar luz sobre o processo histórico que levou de uma mensagem puramente moral a uma fé positiva em que a crença em uma autoridade diferente da própria razão compromete o próprio núcleo moral ou racional da mensagem cristã (BECKENKAMP, 2009, p. 108-113).

Nessa fase, Hegel busca explicar as causas que fizeram o cristianismo ser considerado uma religião dotada de autoritarismo. $O$ jovem filósofo, a fim de investigar tais motivos, compara Jesus a Sócrates. O primeiro utilizava-se de discursos por meio de parábolas, de forma extremamente didática, com um caráter pessoal, bem como utilizava-se de alguns rituais para "enfeitar" suas pregações, com a convicção de ser o "filho de Deus" e "o caminho, a verdade e a vida". O segundo não se utilizou de uma positividade, mas sim do diálogo, sem praticar qualquer "culto a sua personalidade”.

A positividade da religião cristã é um obstáculo à liberdade. O cristianismo, na sua essência, afasta-se da razão, coage o ser humano, causa temor, é dotado de um caráter heterônomo e autoritário, torna o indivíduo escravo da sua legalidade. E assim como a religião cristã, o judaísmo, por não emanar do povo, também seria um exemplo de religião que possui as características acima. Além do mais, as instituições religiosas cometem abusos em seus rituais, causando "fanatismo" nos indivíduos, comprometendo assim a "liberdade no exercício da cidadania”.

\section{Período de Frankfurt (1797-180o): separação do pensamento moral kantiano}

Nessa fase, Hegel escreveu textos, intitulados por Nohl como $O$ espírito do cristianismo e seu destino, cuja ideia central é a crítica da oposição entre razão e natureza sensível, sendo ainda influenciado por Hölderlin quanto à separação do pensamento kantiano, principalmente na primeira fase do jovem filósofo em Frankfurt. Inicialmente, a sociedade grega ainda era vista como um ideal a ser alcançado, em virtude da união entre o ser humano e a natureza, sem que haja uma submissão há um só Deus que cerceia a liberdade desse mesmo ser humano. Mas, tal pensamento é aos poucos flexibilizado por Hegel. 
No primeiro momento de Frankfurt, Hegel questiona o conceito de sumo bem concebido por Kant, busca revelar que o papel do cristianismo foi de afastar a positividade religiosa, bem como qualquer possível legalismo de cunho moral e jurídico. O judaísmo concernente ao Antigo Testamento causa a separação do homem com a natureza. Essa ruptura é apresentada através da história de Abraão que se afasta de seu povo, dissocia-se de uma vida com harmonia, nega a pluralidade de deuses, aceita sacrificar seu próprio filho, acreditando apenas em um único Deus que lhe oferece a segurança imprescindível para a sua existência e ainda possui uma "voz" que lhe conduz a "terra prometida". A figura de Noé também retrata a separação entre o homem e a natureza quando da passagem bíblica do dilúvio. Esse escrito relata a existência de uma natureza agressiva afastada das noções de amizade e de amor. Além desses dois personagens lendários, Moisés também é lembrado como aquele que recebeu os dez mandamentos desse único Deus.

Como visto, Hegel chega no último ano em Berna a descrever a positividade de uma religião como resultado de uma reflexão objetivante, na qual o sujeito racional reflete as consequências da impotência de sua própria razão em um objeto estranho ou exterior a ele mesmo, a cuja legislação caberia, então, submeter-se incondicionalmente (cf. GW 1, 356-357). Em Berna, Hegel chega a essa conclusão no âmbito de seus estudos sobre positividade da religião cristã, revelando um cristianismo dogmático e positivo em que finalmente valem tão somente leis heterônomas a ser seguidas por provirem da vontade de um Deus transcendente.

Agora, nos primeiros tempos em Frankfurt, Hegel procura descobrir a origem da positividade das leis morais e das crenças religiosas, não mais no desenvolvimento do cristianismo, mas no antigo judaísmo. Situando, assim, suas investigações sobre o processo de objetivação e positivação da moral e da religião no seio do judaísmo veterotestamentário, Hegel libera, ao mesmo tempo, o cristianismo para uma nova ordem de interrogações, que se estudará em seguida. O resultado das investigações sobre o cristianismo levadas a cabo em Berna foi o registro da estreita ligação entre a positividade da religião cristã e a heteronomia da legislação, tanto moral como jurídica. Na primeira fase de Frankfurt, Hegel procura mostrar que o cristianismo constituiu originariamente uma tentativa de superar a positividade religiosa e o legalismo moral e jurídico, atribuídos agora ao espírito judaico. Neste contexto, o cristianismo primitivo já não é visto como mensageiro de uma moral pura, como defendida por Kant e Fichte, mas como a religião do amor, capaz de superar as contraposições inerentes ao ponto de vista da moralidade (BECKENKAMP, 2009, p. 133-134).

O judaísmo é incompatível com a ideia de "cidadãos livres", haja vista que o homem se torna um servo desse Deus. Nesse ponto, o cristianismo retorna ao foco de Hegel. Segundo o jovem filósofo, Jesus insurge-se contra o legalismo dos judeus e o judaísmo estabelece uma separação evidente entre a razão humana e a natureza. 
Hegel, ainda, expõe que o moralismo kantiano também causa um "afastamento de si mesmo", pensamento este que deve ser superado. A unidade pregada pelo povo judeu reflete uma dominação dos impulsos por uma lei moral que reprime o homem. Não há uma ligação entre os judeus e o sagrado, a satisfação física é mais importante que a espiritual, o Deus exaltado por eles é um Senhor sem escrúpulos, que constrange a natureza humana.

O momento da superação dessa separação e da "divisão interna do homem" ocorre através do princípio da união inicialmente tratado pelo jovem filósofo no texto intitulado por Nohl como Moralidade, amor, religião. Em Frankfurt, Hegel então concentra seus esforços em desenvolver uma "filosofia da união", buscando encontrar uma religião que unifique o homem com a natureza, assim como una o singular e o universal.

A crítica dessa divisão interna do homem, tornada perpétua do ponto de vista moral do pensamento kantiano, ganha contornos mais nítidos e maior consistência no contraste com o princípio da união, introduzido como momento da superação da separação. No período de Frankfurt, o desenvolvimento mais importante de Hegel se dá no âmbito de uma filosofia da união, que aborda e ensaia diversas repostas à questão da unidade. [...] A religião do amor ou da união pura torna possível que o homem se encontra consigo mesmo como totalidade, realizando a união dos homens, não apenas em momentos particulares, como no amor enquanto sentimento individual, mas em sua totalidade. Por isso a religião cristã constitui o verdadeiro complemento do amor, sendo nela a união completa (BECKENKAMP, 2009, p. 142-160).

Para Hegel, Jesus Cristo sendo para o cristianismo um ser humano ao mesmo tempo que também é filho de Deus, faz com que essas características atribuam a religião cristã um caráter especial. A "consciência-de-si religiosa” traduz a consciência do ser humano em reconhecer-se a imagem de Deus e acreditar que dentro de si mesmo existe um valor infinito e um destino eterno. $\mathrm{O}$ mundo espiritual é então o verdadeiro mundo do ser humano. Para que o homem liberte-se do mundo natural, é preciso que se reconheça um ser dotado de espiritualidade.

Nessa fase, portanto, Hegel começa a entender Jesus como um mensageiro da filosofia da união. O que complementa a moralidade é o amor, que mesmo sendo um sentimento nobre, precisa ainda da religião para ser completado. A religião cristã ganha status de real complementação do amor, e consequentemente concebe a "união completa" entre o ser humano e o divino. No entanto, tal pensamento somente ganhará mais consistência no período de Iena.

\section{Período de Iena (1801-1807): início do sistema filosófico de Hegel}

No período de Iena, Hegel inicia a formação de seu próprio sistema cujo texto 
principal é o Fragmento de sistema de 180o. Nesse momento, ele entende a filosofia como ciência e a ideia do "ser absoluto" ligado à uma questão lógica. Há uma aproximação com o pensamento de Schelling, assim como um afastamento de Fichte e de Kant. Schelling e Hegel buscavam fundamentalmente superar a separação kantiana entre "sujeito e objeto", “intuição e conceito", e, ainda, entre "razão e entendimento".

De acordo com Fichte numa concepção determinista da natureza, esta é produto exclusivo da razão humana. Todavia, Schelling não compartilha dessa ideia, pois para o filósofo existe uma organização na natureza, cujo princípio criador é externo ao "Eu" do ser humano. Defende ainda uma concepção panteísta na qual Deus está presente em todas as coisas e se reconhece na natureza através do homem. O conceito de "razão absoluta" sob uma ótica de totalidade foi a melhor solução apresentada pelo seu idealismo objetivo.

Apesar de ter começado ainda em Frankfurt a lançar os primeiros fundamentos de sua filosofia, Hegel passará os anos em Iena estudando e elaborando o delineamento essencial de seu sistema. Assim, pode-se dizer que neste período se assiste à formação dos diversos membros do grande organismo que é a filosofia hegeliana. Antes de ir para Iena, Hegel escreve a Schelling, em uma carta de novembro de 1800 enviada de Frankfurt: "Em minha formação científica, que começou com necessidades subordinadas dos homens, tive de ser impelido para a ciência, e o ideal da juventude teve de se transformar na forma da reflexão ao mesmo tempo em um sistema”. O pensamento filosófico como ciência e na forma de sistema será o objetivo dos esforços de Hegel em Iena (BECKENKAMP, 2009, p. 191).

Destarte, com a publicação no ano de 1807 da Fenomenologia do Espírito, é que Hegel distancia-se do pensamento de Schelling e inicia seu pensamento dialético, assim como percebe a importância da história da filosofia como "expressão do desenvolvimento do espírito", ou seja, a filosofia é a expressão mais elevada do espírito, diferente do que ocorria em Frankfurt onde ainda se atribuía este status à religião cristã. Hegel, iniciando então sua fase madura, explica que as civilizações remotas são consideradas etapas imprescindíveis as quais o "espírito" transpôs a fim de que o ser humano percebesse a consciência de sua liberdade, e esta é "nexo racional" que rege a história universal. Portanto, o estudo da filosofia da história hegeliana deve ser objeto de um estudo mais detalhado.

\section{Considerações finais}

O estudo da religião e da teologia é sempre atual. O jovem Hegel mostrou-se preocupado com as questões religiosas de sua época, assim como contemporaneamente alguns estudiosos mostram-se interessados pela figura de Jesus Cristo e na ideia de um Deus que rege a nossa existência. Deste modo, conhecer os 
textos de juventude de Hegel são essenciais para o entendimento das questões que o perturbavam e que, posteriormente, permitiram a formação de seu pensamento maduro.

A partir dos escritos teológicos, percebe-se que, para Hegel, os indivíduos devem governar a si mesmos conforme suas consciências e concepções, pois, a natureza do ser humano é ser livre. Porém, esse tema, diante da sua densidade, merece maior atenção em estudos futuros e mais profundos das obras posteriores aos escritos de juventude do filósofo alemão.

\section{Referências}

BECKENKAMP, J. O jovem Hegel: formação de um sistema pós-kantiano. São Paulo: Loyola, 2009.

Dois fragmentos de Hegel do período de Iena: "DIE IDEE DES ABSOLUTEN WESENS” (1801) e "DAS WESEN DES GEISTES” (1803). Revista Eletrônica Estudos Hegelianos. Ano 8, nํ14, Junho - 2011: 67-72. Disponível em:

<http://www.hegelbrasil.org/reh_2011_1_art5.pdf>. Acesso em: 10 mar. 2016.

BORGES, B. I. A fenomenologia do espírito como romance de formação. Veritas, v. 55, n. 3, set./dez. 2010, p. 158-177.

GRUPILLO CHAGAS, A. E. Judaísmo, cristianismo e idealismo alemão: a propósito da correspondência entre F. Rosenzweig e E. Rosenstock sobre Hegel. Revista do Instituto Histórico e Geográfico de Sergipe, v. 45, p. 76-83, 2015.

HEGEL, G. W. F. A fenomenologia do espírito. Coleção Os Pensadores. ıª ed. São Paulo: Abril Cultural, 1974 .

Cultural, 1974. Introdução à História da Filosofia. Coleção Os Pensadores. São Paulo: Abril

HYPPOLITE, J. Introdução à Filosofia da História de Hegel. Trad. de José Marcos Lima, Rio de Janeiro, Elfos, 1995.

SINGER, P. Hegel. Coleção Mestres do Pensar. São Paulo: Loyola, 2003.

Submissão: 01.04.2017 / Aceite: 10.05.2017 